\title{
A NOÇÃO HEIDEGGERIANA DE CUIDADO (SORGE) E A CLÍNICA PSICOTERÁPICA
}

Roberto Novaes de Sá

SINTESE - À luz da analítica do Dasein, apresentada em "Ser e Tempo", o trabalho discute a possibilidade de fundamentação da relação psicoterápica a partir da noçăo de "cuidado" (Sorge). Desta perspectiva, a questão da verdade na clínica desloca-se do âmbito das teorias e das técnicas psicológicas para aquele da existência, em que está sempre em jogo o próprio ser do homem. Ao mesmo tempo, formece ao cuidado terapêutico uma base ontológica que não provém nem da teorização científica nem de uma concepção humanista, subjetivista e sentimental.

PALAVRAS-CHAVE - Cuidado. Daseinsanalyse. Heidegger. Psicoterapia.
ABSTRACT - Based on Daseinsanalysis, presented in "Beeing and Time", this work discusses the possibility of grounding psychoterapic relation to the concept of "care" (Sorge). From this perspective, the question of truth in clinic displaces from the realm of psychological theories and techniques to that of existence, in which the human beeing is always at play. At the same time, it gives the therapeutic care an ontological basis that does not come from cientific theorization nor from a humanistic, subjective and sentimental conception.

KEY WORDS - Care. Daseinsanalysis; Heidegger. Psycotherapy.

\section{0 "cuidado" como ser do Dasein}

O ser do homem no pensamento de Heidegger não está determinado a partir de nenhuma interpretação metafísica do ser dos entes. O Dasein é o ente cujo ser está em jogo no seu existir. Mas esta liberdade para ser é, de início e na maioria das vezes, ignorada enquanto tal, isto é, o Dasein relaciona-se de modo involuntáno com suas possibilidades de ser, levando uma vida imprópria (esquecida de seu poder ser mais próprio) e impessoal. Toma-se, portanto, por um ente cujo ser fosse simplesmente dado a priori, compreende-se a partir dos entes encontrados no mundo.

É o fenômeno da angústia que, dissolvendo o sentido público, mediano e impessoal dos entes intramundanos, lança o Dasein diante da liberdade e da responsabilidade de singularizar-se na escolha de suas possibilidades próprias. Se, do ponto de vista ôntico, o Dasein encontra-se inicialmente num modo de ser impróprio e impessoal, tomando-se por um ente cujo modo de ser é simplesmente dado,

Professor Adjunto do Departamento de Psicologia da Universidade Federal Fluminense, UFF. 
a singularização apontada com o fenômeno da angústia só é possível porque, do ponto de vista ontológico, o Dasein já é sempre originariamente a abertura em que se dá o "estar em jogo" do ser. Mesmo numa atitude imprópria e impessoal, o Dasein sempre precede a si mesmo por já ser-no-mundo. Os modos de ser revelados pela analítica do Dasein não são, portanto, estados ou condições subjetivas alternadas ou superáveis temporalmente, mas possibilidades existenciais sempre presentes e articuladas estruturalmente.

Heidegger (1927, cap. VI) propõe apreender a totalidade estrutural do Dasein na unidade da cotidianidade mediana, imprópria e impessoal e das possibilidades de transformação que já sempre lhe pertencem. Essa unidade existencialontológica do Dasein ele denomina com o termo cuidado Sorge: "o ser do Dasein diz preceder a si mesmo por já ser em (no mundo) como ser junto a (os entes que vêm ao encontro dentro do mundo)" (1927, p. 257). A designação do ser do Dasein como "cuidado" é um desenvolvimento integrador da multiplicidade estrutural que a análise fenomenológica do "ser-no-mundo" revela em "Ser e Tempo". Por não ser nenhuma "substância" ou "ser-simplesmente-dado", o Dasein se dá sempre "no-mundo", numa estrutura de significância, num contexto de relações.

São diferenciados, por Heidegger, dois modos fundamentais do cuidado Sorge: nas relações do Dasein com os entes cujo modo de ser é simplesmente dado, ele emprega o termo "ocupação" Besorgen; quando se trata dos entes que têm o modo de ser do Dasein, ele usa o termo "preocupação" Fürsorge. O cuidado não se reduz ao desejo nem diz respeito a algum tipo específico de atitude psicológica protetora ou negligente em relação aos entes, antes, pelo contrário, essas possibilidades fundam-se no cuidado: "A condição existencial de possibilidade de 'cuidado com a vida' e 'dedicação' deve ser concebida como cuidado num sentido originário, ou seja, ontológico” (1927, p. 265).

Para apreender melhor este sentido originário do "cuidado", podemos pensar o Dasein, ao invés de "ser-ai", como "ser-o-ai", o "ai" enquanto "mundo", abertura em que se revela o sentido (o ser) dos entes à luz do cuidado. O homem nunca é primeiro o "sujeito" de um lado que se opõe aos "objetos" do outro lado. A essência do homem co-pertence à abertura de sentido do ser na qual um dia pôde vir a ser historicamente a relação "sujeito-objeto". Isso significa que a realização das possibilidades de ser do Dasein num modo próprio ou impróprio, autêntico ou inautêntico, singular ou impessoal, não é apenas uma questão de transformação interna, indiferente ao ser dos entes que o rodeiam no mundo ou apenas afetandoos posteriormente por uma mudança no modo de representá-los. Enquanto "clareira" (Lichtung) em que se revela o ser dos entes, qualquer transformação do Dasein é imediatamente uma transformação do mundo, pois traz à luz outros aspectos do ser dos entes que através dele se mostram. Por isso diz Medard Boss:

"Não há, conseqüentemente, nenhum fenômeno da consciência humana que não deva e não possa ser entendido no fundo como um chamado e uma advertência para cumprir a missão humana de guardião e pastor de tudo aquilo que tem que aparecer, que ser, e que quer se desdobrar na luz de umą determinada existência humana" (1988, p. 39). 


\section{A doença como restrição da liberdade e distúrbio do sentido}

Se o Dasein é, fundamentalmente, abertura de correspondência ao sentido do ser dos entes e do ser enquanto tal, um modo de ser doente não se caracteriza, para a Daseisanalyse, tanto por seu conteúdo positivo quanto pelo aspecto de privação que ele encerra. O que faz com que se diga de um Dasein que está doente não é um modo específico de correspondência, que a princípio é uma possibilidade de qualquer Dasein, mas o fato de encontrar-se limitado a esse modo específico e, assim, impossibilitado de corresponder a outros apelos de sentido que se façam prementes em seu existir. Todo estar doente é sempre uma limitação mais ou menos grave das possibilidades de relação que o homem pode manter no mundo, portanto, de sua liberdade. Para Heidegger (1987, p. 199), à psicoterapia concerne essencialmente o problema da liberdade:

"Empregamos a psicologia, a sociologia e a psicoterapia para ajudar o homem a ganhar adaptação (Anpassung) e liberdade em seu sentido mais amplo. Isso diz respeito (também) à medicina e à sociologia, porque todo distúrbio sociológico e patológico é um distúrbio da adaptação e da liberdade do homem singular."

É importante lembrar, no entanto, que o Dasein em seu modo cotidiano e mediano de ser tende de início ao fechamento, isto é, ao encerramento de todo sentido dos entes num horizonte de instrumentalidade. Tal fechamento, portanto, não caracteriza, por si só, nenhuma patologia. Toda abertura define-se por limites e contém, enquanto abertura, a possibilidade de fechar-se. Para que se possa falar em "distúrbio", é preciso que o limite de abertura ao sentido do Dasein esteja seriamente questionado por uma demanda de sentido que não se satisfaça em seu interior e que, assim, evidencie esse limite como restrição da liberdade de corresponder aos apelos de sua situação existenciária.

De início e na maior parte das vezes, o homem encontra-se num mundo cujo sentido dos entes é simplesmente dado, não sendo, portanto, tema de uma apropriação reflexiva. Apenas quando uma coisa ou acontecimento escapa ao seu lugar esperado na rede de significância instituída como mundo, surge o estranhamento, a angústia e a demanda, nem sempre correspondida, de tematização do sentido. Essa demanda pode assumir dois niveis de abrangência distintos. No primeiro, questiona-se o sentido de um ente intramundano a partir do horizonte de sentido já estabelecido. No segundo, impõe-se um questionamento mais radical que põe em jogo o próprio horizonte de sentido enquanto tal e, portanto, os limites do mundo (do Dasein como abertura). É neste caso que pensamos ser mais pertinente falar em distúrbio ou crise na cotidianidade do Dasein.

Deve-se atentar para a ambigüidade que uma tal compreensão de distúrbio encerra. Se por um lado, ele foi caracterizado essencialmente como restrição das possibilidades de livre correspondência ao sentido, que define o Dasein, por outro, ele é parte intrínseca da dinâmica de apropriação desta mesma liberdade que, de início, o Dasein, em seu modo mediano, vive de modo impróprio e inautêntico. 
$\mathrm{O}$ distúrbio, como o vir à luz problemático de um horizonte de sentido antes não manifesto e assegurador do sentido simplesmente dado de todas as coisas e eventos intra-mundanos, não é uma escolha voluntária do Dasein e muito menos um questionamento meramente teórico sobre as representações mais adequadas aos objetos de suas relações. O distúrbio é a ameaça à estabilidade da estrutura de sentido, chamada mundo, a partir de um acontecimento que se impõe ao Dasein como sem sentido ou como aceno de possibilidades de sentido radicalmente outras com relação ao horizonte dado.

A psicoterapia como espaço de acolhimento e concentração do distúrbio, isto é, do questionamento do horizonte de sentido em que se constitui o Dasein em certo momento existenciário, tão pouco é um processo voluntariamente conduzido pelo terapeuta no plano das representações mais adequadas em face à demanda de sentido imposta pela vida ao cliente. A questão que instala a terapia e nela se instala é a mesma já imposta pela vida. Portanto, não se pode atribuir à relação terapêutica nenhum privilégio no sentido de maior objetividade, neutralidade ou afastamento. Podemos apenas dizer que o espaço terapêutico se mantém no esforço de sustentar a questão, enquanto questão concernente ao poder-ser próprio do Dasein, até o limite em que seu apelo suscite novas possibilidades de correspondência.

\section{Sobre a transferência}

Sabe-se que um dos elementos centrais em que se baseia a técnica psicanalítica é a noção de "transferência" (Übertragung). Segundo Freud, "[forma-se] [...] entre o paciente e o médico uma relação emocional especial, relação que vai muito além dos limites racionais" (1923, p. 300). E continua ele:

"Essa transferência, tanto em sua forma positiva quanto negativa, é utilizada como arma pela resistência; porém, nas mãos do médico, transforma-se no mais poderoso instrumento terapêutico e desempenha um papel que dificilmente se pode superestimar na dinâmica do processo de cura" (Idem).

A importância desta "relação emocional" foi reconhecida na prática clínica por Freud e é comprovada diariamente por todos que vivem a experiência clínica. Denominá-la, no entanto, como "transferência", só faz sentido a partir de uma compreensão que se baseia nas noções de "causalidade" e "subjetividade intrapsíquica". Isto é, a história de vida é vista como uma seqüência causal de acontecimentos em que o anterior determina o posterior e as representações estabelecidas no interior do sujeito por esses eventos determinantes é transferida e projetada posteriormente sobre um outro objeto. Esse objeto da transferência, no caso o terapeuta, enquanto ente cujo modo de ser é entendido como simplesmente dado, nada tem a ver obrigatoriamente com as representações e afetos que a ele se transferem. Freud amplia o campo de aplicação da noção dizendo (1912, p. 141) que a transferência não é um fenômeno exclusivo da psicanálise, mas estende-se de forma não reconhecida a outros tratamentos e relações institucionais. 
De uma perspectiva daseinsanalytica, colocam-se os seguintes questionamentos: existe sempre uma situação histónica determinante e determinável que seja transferida para outras situações? Existe algum suporte neutro para onde as representações são transferidas, isto é, há algum objeto simplesmente dado cujo sentido seja anterior a toda relação e portanto não seja transferido? Segundo Heidegger (1987, p.210):

"A situação (Befindlichkeit) ou disposição (Gestimmtheit) é um caráter fundamental do Dasein e pertence a todo e qualquer comportamento. Cada comportamento já é sempre em princípio orientado, por isso não faz nenhum sentido falar de 'transferência' (Übertragung). Não é necessário ocorrer nenhuma transferência, porque a respectiva disposição, a partir da qual e em relação a qual, somente, tudo que vem ao encontro pode mostrar-se, já está sempre lá. Como parte da respectiva disposição, um ser humano que vem ao encontro de outro mostra-se, também, relacionado a esta 'abertura' (Entschlossenheit) Disposição (Gestimmtheit)."

Conforme foi visto, o Dasein como "abertura" já está sempre numa précompreensão do ser dos entes. Não se trata de uma mera compreensão teórica, neutra do ponto de vista afetivo. A pré-compreensão em que o Dasein já sempre se encontra é intrinsecamente orientada por uma "disposição" (Stimmung). A disposição, neste sentido, não é um fenômeno psicológico, mas, antes, o existencial a partir do qual é possível qualquer variação psíquica dos afetos ou "estados de ânimo". "A disposição coloca o Dasein diante do fato de seu 'aí' (Da) que, como tal, se lhe impõe como enigma inexorável” (Heidegger, 1927, p. 190).

A colocação do fenômeno observado por Freud em sua prática clínica, o estabelecimento de uma relação afetiva entre cliente e terapeuta, sob esta perspectiva daseinsanalytica em nada diminui sua importância terapêutica, apenas lhe fornece uma base mais simples e rigorosa que permite apreendê-lo em toda sua abrangência sem construções metapsicológicas complexas e arbitránias. É pela tematização e apropriação da pré-compreensão já sempre "disposta" em que se encontra, que o Dasein amplia sua liberdade de correspondência aos diversos envios que lhe vêm ao encontro no mundo.

\section{A compreensão terapêutica e o "ser-com"}

O modo de compreensão do outro já é sempre uma dimensão intrínseca do modo de "ser-com-o-outro". Isso não vale menos para a relação terapêutica do que para qualquer outra. O "ser-com", por sua vez, entendido como ser com outros Daseins, é inerente à constituição fundamental do homem como "ser-nomundo". Assim como a partir do mundo, enquanto estrutura de significância, as coisas nos vêm ao encontro numa rede de referências que lhes dão sentido, também os outros nos vêm ao encontro nesse conjunto estrutural.

Heidegger (1927, p. 168-169) nos dá o exemplo do mundo do artesão, no qual o mesmo horizonte de referência que revela as coisas como "matéria prima", "instrumento" ou "obra", faz vir ao encontro o outro como "produtor", "fornecedor" ou "usuário". Diz ele: 
'Os outros que assim 'vêm ao encontro', no conjunto instrumental à mão no mundo circundante, não são algo acrescentado pelo pensamento a uma coisa já antes simplesmente dada. Todas essas coisas vêm ao encontro a partir do mundo em que elas estão à mão para os outros. Este mundo já é sempre previamente o meu."

Do mesmo modo, podemos dizer que no mundo do terapeuta, em seu modo cotidiano e mediano, o outro vem ao encontro no âmbito de certas referências dominantes que tendem a encobrir qualquer surpresa ou estranhamento. $\mathrm{O}$ outro já é sempre previamente dado como "cliente", "paciente", "doente", subjetividade intrapsíquica a ser conhecida em sua determinação estrutural. Como em qualquer outra área de "ocupação", também o contexto mediano da psicoterapia tende a ser, na maior parte das vezes, dominado por modos indiferentes de convivência, isto é, modos em que a identidade e a alteridade radicais em jogo no "ser-com" são encobertas pelo encontro do outro como ente (sujeito) simplesmente dado.

Como foi dito anteriormente, Heidegger distingue dois modos básicos do "cuidado" (Sorge), a essência relacional do Dasein: por "ocupação" (Besorgen), nomeia ele o "cuidado" para com os entes intramundanos cujo modo de ser revela-se a partir da utilidade instrumental, como vimos a pouco no exemplo do artesão; já por "preocupação" (Fürsorge), designa ele o "cuidado" para com os entes que têm o modo de ser do Dasein. A "preocupação" funda-se na constituição essencial do Dasein enquanto "ser-com".

O modo cotidiano e mediano da "preocupação" com os outros é a indiferença, a ausência de surpresa e a evidência, que também caracterizam a "ocupação" com as coisas enquanto instrumentos à mão. Além da "indiferença", Heidegger fala em duas outras possibilidades da "preocupação" que são de extrema importância para a reflexão clínica. A primeira diz respeito ao modo de "preocupação" que "substitui" (einspringt) o outro assumindo suas "ocupações" para liberá-lo delas ou devolvê-las posteriormente como algo já pronto. "Nessa preocupação, o outro pode tornar-se dependente e dominado mesmo que esse domínio seja silencioso e permaneça encoberto para o dominado" (1927, p. 174). Cremos ser esse um modo bastante comum do "cuidado" nas formas de terapia que possuem uma teoria ou aspiram a ela, e uma técnica que dêem conta do existir humano.

O segundo modo da "preocupação" que Heidegger menciona é aquele que se "antepõe" (vorausspringt) ao outro não para substituí-lo, mas para pô-lo diante de suas próprias possibilidades existenciárias de ser. "Essa preocupação que, em sua essência, diz respeito ao cuidado propriamente dito, ou seja, à existência do outro e não a uma coisa de que se ocupa, ajuda o outro a tornar-se, em seu cuidado, transparente a si mesmo e livre para ele" (idem). No âmbito da clínica, portanto, a "anteposição" seria o modo do "ser-com" em que o terapeuta deixa-se apropriar enquanto abertura dialogante para a manifestação das possibilidades próprias do outro. Heidegger diz que esses dois modos da "preocupação", a "substituição" e a "anteposição", são duas possibilidades extremas da "preocupação" não indiferente, na convivência cotidiana se dão inúmeras formas mistas.

Da mesma maneira que a "ocupação". com as coisas, enquanto entes simplesmente dados à mão, é guiada por uma "circunvisão" (Umsicht) em que se 
articulam material, instrumento, obra, usuário e uso, também a "preocupação" norteia-se por uma compreensão prévia a partir da qual o outro se dá como copresente no mundo. Esses modos de ver previamente constitutivos da "preocupação" Heidegger denomina como "consideração" (Rücksicht) e "tolerância" (Nachsicht). Segundo as notas explicativas do Prof. Carneiro Leão à tradução brasileira de "Ser e Tempo" (p. 314), a "consideração" "indica uma maneira de ver, que leva em conta a diferença e a importância de tudo com que se lida [...]" e a "tolerância" "exprime o empenho de correr atrás, aceitando as tensões, os limites e as características diferenciais das situações e modos de ser". Deve-se ressaltar, no entanto, que ambas acompanham também os modos deficientes da "preocupação" na forma de "desconsideração" e da "tolerância" indiferente.

Em qualquer de seus modos a convivência, para a perspectiva daseinsanalytica, não é o encontro a posteriori de sujeitos isolados, antes definidos a partir de si mesmos. O "ser-com" é uma dimensão ontológica constitutiva do Dasein enquanto tal. Cada Dasein já é sempre "no-mundo-com-o-outro" e o modo mais próprio de ser "si-mesmo" não exclui, mas implica obrigatoriamente algum modo específico de "ser-com". O problema da compreensão do outro não se reduz, portanto, jamais, a uma questão de metodologias e técnicas, ao contrário, essas somente são possiveis enquanto desdobramento temático da pré-compreensão do outro em que já sempre se encontra o Dasein segundo seu modo de "ser-no-mundo". Tal colocação é essencial para a psicoterapia, pois desloca a questão da verdade na clínica do âmbito das teorias e das técnicas para aquele da existência, em que está sempre em jogo o próprio ser do homem. Ao mesmo tempo, fornece ao cuidado terapêutico uma possibilidade de fundamentação ontológica que não provém nem da teorização científica nem de uma concepção humanista subjetivista e sentimental.

\section{Referências bibliográficas}

BOSS, Medard. Angústia, culpa e libertaçăo. São Paulo: Duas Cidades, 1988.

FREUD, Sigmund (1912). A dinâmica da transferência. In: E.S.B. Rio de Janeiro: Imago, 1980. v. 12.

HEIDEGGER, Martin. (1927). Ser e tempo. Petrópolis: Vozes, 1989.

Z Zollikoner Seminare. Frankfurt am Main: Vittorio Klostermann, 1987. 